Leider reichte die geringe Menge des zu Gebote stehenden Materials nicht hin, weitere Untersuchungen anzustellen.

Wenn nun im vorliegenden Falle die Wassermenge und der Gehalt an organischen Stoffen (Fibrin und Albuunin) ziemlich mit den Angaben von Nasse und Geiger übereinstimmen, so ist dieses weniger bei den Mine:ralstoffen, insbesondere bezüglich der Kohlensäure und Phosphorsäure, der Fall, von denen erstere in der Asche fehlte, letztere dagegen in zienlicher Menge vorhanden war. Auch der relativ ziemlich grosse Gehalt an Kali ist bis jetzt noch nicht beobachtet worden. (Verhandl. der Wirzb. phys.-med. Gesellsch. - Journ. fih prakt. Chem. Bd. 70.)

$B$.

\title{
Ueber die Natur der thierischen Krystallinse,
}

haben Valanciennos und Frémy sehr interessante Versuche angestellt, die zu folgenden Resultaten geführt haben.

1) Die Krystallinse der Säugethiere ist aus in Wasser unlöslichen Fusern gebildet, die in der Mitte der Linse durch eine eiweisshaltige Substanz zusammengehalten werden, welche bei $65^{\circ}$ gerinnt. Durch längere Behandlung mit Alkohol wird sie durchscheinend und nimmt einen ambrähnlichen Geruch an. Mehr nach dem Rande der Linse hin werden die Fasern ebenfalls durch einen eiweissartigen Körper vereinigt, der indessen durch Kochen nicht gerinnt, und durch Chlorwasserstoffsäure nicht gebläuet wird. Valanciennes und Frémy nennen îhn Metalbumin.

2) Diese beiden, anatomisch verschiedenen Substanzen, die zwei verschiredene Theile der Säugethier-Krystallinse ausmachen, müssen durch besondere Namen unterschieden werden, wozu von den Verf. die Namen Endophacin für die Centralschicht und Exophacin für die iussere Schicht in Vorsohlag gebracht werden.

3) Die Krystallinse der Vögel, Reptilien und Batrachier weicht von derjenigen der Säugethiere wenig ab.

4) Die Krystallinse der Fische besteht ebenfalls aus zwei verschiedenen Theilen. Der äussere Theil oder das Exophacin ist aus Metalbumin zusammengesetzt, der innere dagegen aus einer eiweissartigen, festen und im Wasser unlöslichen Substanz, dem Phaconin, gebildut. (Journ. de Pharm. et de Chim. Juill 1857. p.5ff.) Hendess. 